\title{
A Novel Biosensor Based on Terminal Protection and Fluorescent Copper Nanoparticles for Detecting Potassium Ion
}

\author{
WenJing Deng, Chang Liu, YanLei Hu, RuQin Yu, TingTing Chen, ${ }^{\dagger}$ and $\mathrm{Xia}^{\mathrm{CHU}} \mathrm{CH}^{\dagger}$ \\ State Key Laboratory of Chemo/Bio-Sensing and Chemometrics, College of Chemistry and Chemical Engineering, \\ Hunan University, Changsha 410082, P. R. China
}

\begin{abstract}
A novel biosensor for sensitively detecting potassium ion $\left(\mathrm{K}^{+}\right)$has been developed based on fluorescent copper nanoparticles (Cu NPs). In our design, we employ a label-free single-strand DNA (ssDNA) that contains two parts. One is $3^{\prime}$-terminus structure-switching aptamers (SSAs) that can fold into G-quadruplex after binding with its target $\mathrm{K}^{+}$. The other is $5^{\prime}$-terminus poly thymine (polyT) which works as a template to construct fluorescent Cu NPs. After incubating with $\mathrm{K}^{+}$, the part SSAs go through target-induced conformational changes. Benifiting from the exceptional digestion ability of exonuclease I (Exo I), the G-quadruplexes display effective resistance to nuclease digestion, so that $5^{\prime}$-terminus polyT remains and the in situ formation of $\mathrm{Cu}$ NPs provides a turn-on fluorescent signal that is used to evaluate the concentration of $\mathrm{K}^{+}$. The recovery of the fluorescence intensity is linearly correlated with the $\mathrm{K}^{+}$concentration in the range of 0.05 to $1 \mathrm{mM}$ with a detection limit of $0.05 \mathrm{mM}$. Compared with some methods, this assay is cost-effective and facile with high specificity. Meanwhile, this excellent strategy shows a great potentiality in other sensing approaches that can study the interaction between similar SSAs and different specific targets.
\end{abstract}

Keywords Fluorescent copper nanoparticles, potassium ion, Exo I, G-quadruplex, terminal protection

(Received July 7, 2017; Accepted August 23, 2017; Published December 10, 2017)

\section{Introduction}

Potassium ion $\left(\mathrm{K}^{+}\right)$is one of the most necessary cations in the human body, since it has a great influence on many regulating physiological functions, including hyperpolarization in the signal transduction of neurons, cellular osmotic pressure, apoptosis, $\mathrm{pH}$ balance, muscular strength, and renal function. ${ }^{1-5}$ Therefore, it is still highly essential and urgent to develop novel $\mathrm{K}^{+}$probes or efficient detecting approaches with high specificity and sensitivity.

Up to now, many $\mathrm{K}^{+}$probes, such as nucleic acid-based aptamers, have been reported. ${ }^{6-8}$ Nucleic acid-based aptamers that are generated by a systematic evolution of ligands with an exponential enrichment (SELEX) process and obtained through selections, ${ }^{9}$ are artificial single-stranded DNA (ssDNA) or RNA sequences that can recognize specific biological molecules with a wide range, such as small molecules, ${ }^{10}$ organic compound, ${ }^{11}$ proteins ${ }^{12}$ or even whole cells. ${ }^{13}$ With outstanding stability, high affinity, excellent selectivity, easy modification, as well as low immunogenesis, nucleic acid-based aptamers have successfully attracted the increasing attention of researchers, and have been widely used in food safety, diagnosis, cell imaging and drug delivery. ${ }^{14-18}$

Among nucleic acid-based aptamers, different from normal affinity adsorption, a kind of aptamers, named structureswitching aptamers (SSAs), which are able to experience

$\dagger$ To whom correspondence should be addressed.

E-mail: xiachu@hnu.edu.cn (X. C.); chenting1104@hnu.edu.cn (T. T. C.) conformational changes and to fold into secondary structures, like a G-quadruplex or a Y-shape structure when binding with the specific targets, have been extensively utilized to construct various biosensors. ${ }^{19,20}$ If the secondary structures happen to be at the end of the ssDNA, they can effectively resist degradation from the 3'-termini specific exonuclease I (Exo I). Based on the terminal protection, there is a growing number of studies concerning the interaction between nuclear acids and specific targets. For example, Jiang et al. reported on the quantitative analysis of the interaction of folate with a tumor biomarker of the folate receptor. ${ }^{21}$ Wei et al. developed a novel method to sensitively detect adenosine triphosphate (ATP). ${ }^{22}$ All of the studies indicate that terminal protection is a desirable strategy to fabricate new biosensors, and are prospectively used in more sensing platforms.

Herein, inspired and encouraged by the structure-sensitive terminal protection strategy, we combine SSAs with metal nanoparticles. Metal nanoparticles have attracted increasing attention due to their desirable properties, including easy synthesis, low toxicity, and sequence dependence. Recently, nanoparticle-based analytical methods were explored in many sensing detecting platforms, such as heavy metal ions, ${ }^{23}$ antibodies, ${ }^{24}$ and enzymes. ${ }^{25}$ In our study, we form poly thymine (polyT)-templated fluorescent $\mathrm{Cu}$ NPs to work as the fluorescent signal, since Qing et al. proved that single-stranded polyT could be applied as an excellent template to form fluorescent $\mathrm{Cu}$ NPs. ${ }^{26}$ Compared with other metal nanoparticles, $\mathrm{Cu}$ NPs are low-cost and easy to synthesize. Additionally, the polyTtemplated fluorescence produced is highly efficient and accomplish within a few minutes after the start of construction under suitable conditions. ${ }^{27,28}$ In this study, we explore a simple 
and rapid strategy to label-free detect $\mathrm{K}^{+}$with the assistance from Exo I, which is capable of distinguishing folding and unfolding aptamers. The sequences of the SSAs we have used are $\left(5^{\prime}-3^{\prime}\right)$ : TGA GGG TGG GGA GGG TGG GGA A, which specifically recognize $\mathrm{K}^{+}$and effectively avoid interferences from other metal ions especially sodium ion $\left(\mathrm{Na}^{+}\right)$, as previously reported, ${ }^{20}$ will take place the conformational change after binding with targets $\mathrm{K}^{+}$. Due to the structural selectivity of Exo $\mathrm{I}$, the 3'-terminus G-quadruplexes display effective resistance to the digestion of Exo I. As a result, 5'-terminus polyT part remained and trigger the formation of $\mathrm{Cu}$ NPs. According to the obvious $\mathrm{Cu}$ NPs fluorescence, we successfully develop a novel method to accomplish a quantitative analysis of the $\mathrm{K}^{+}$ concentration.

\section{Experimental}

\section{Reagents and materials}

HPLC-purified DNA oligonucleiotides were obtained from Shanghai Sangon Biological Engineering Technological Co., Ltd. (Shanghai, China). The sequence was as follows: 5'-TTT TTT TTT TTT TTT TTT TTT TTT TTT TTT TGA GGG TGG GGA GGG TGG GGA A-3'. Exo I was purchased from New England Biolabs (Beijing, China). Potassium chloride ( $\mathrm{KCl})$, sodium chloride $(\mathrm{NaCl})$, magnesium chloride $\left(\mathrm{MgCl}_{2}\right)$, ammonium chloride $\left(\mathrm{MH}_{4} \mathrm{Cl}\right)$, lithium chloride $(\mathrm{LiCl})$ and Calcium chloride $\left(\mathrm{CaCl}_{2}\right)$ were supplied by China National Pharmaceutical Group Corp. (Shanghai, China). Copper sulfate pentahydrate $\left(\mathrm{CuSO}_{4} \cdot 5 \mathrm{H}_{2} \mathrm{O}\right)$ was obtained from Xilong Chemical Co., Ltd. (Shanghai, China). Goldview and ethidium bromide were purchased from Dingguo Changsheng Biotechnology Co., Ltd. (Beijing, China). Sodium ascorbate, tris(hydroxymethyl)-aminomethane (Tris), sodium 4-(2-hydroxyethyl)piperazine-1-ethanesufonate (HEPES), 3-( $N$ morpholino)propane-sulfonic acid (MOPS) were purchased from Shanghai Sangon Biological Engineering Technological Co., Ltd. (Shanghai, China). Human serum was obtained from the Third Xiangya Hospital of Central South University (Changsha, China). All reagents were involved as received without any further purification. Ultrapure water obtained from a Millipore Milli-Q water purification system (Billerica, USA) having an electric resistance $>18.2 \mathrm{M} \Omega$ was used in following experiments.

\section{Apparatus}

Transmission electron microscopy (TEM) was conducted on a field-emission high-resolution 2100F TEM (JEOL, Japan) with a $200-\mathrm{kV}$ acceleration voltage. Inductively coupled plasma mass spectrometry (ICPMS) was operated on an ICPMS 7700 (Agilent, USA). Fluorescence measurements were carried out on an FL-7000 spectrometer (Hitachi, Japan). The fluorescence emission spectra were recorded from 530 to $660 \mathrm{~nm}$ with a $340 \mathrm{~nm}$ excitation wavelength at room temperature. The slits for excitation and emission were set at 5 and $10 \mathrm{~nm}$, respectively.

\section{Target binding and cleavage reaction}

Firstly, a $50-\mu \mathrm{L}$ binding reaction solution $(20 \mathrm{mM}$ Tris- $\mathrm{HCl}$, $2 \mathrm{mM} \mathrm{MgCl}_{2}, \mathrm{pH}$ 7.6) containing $4 \mu \mathrm{M}$ substrate ssDNA and various concentrations of $\mathrm{K}^{+}$was pre-incubated at $20^{\circ} \mathrm{C}$ for 60 min to make sure that the SSAs part of the substrate ssDNA could bind with its target $\mathrm{K}^{+}$, and fold into G-quadruplexes. Then, $20 \mathrm{U}$ Exo I was added to the system and incubated at $37^{\circ} \mathrm{C}$ for a corresponding time. Subsequently, the digestion reaction was ended by heating at $90^{\circ} \mathrm{C}$ for $10 \mathrm{~min}$.

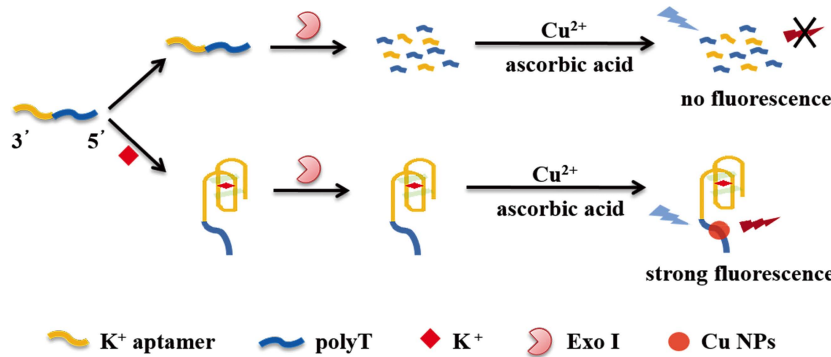

Scheme 1 Schematic illustration of the novel sensing platform for the detection of $\mathrm{K}^{+}$.

\section{The formation of fluorescent $\mathrm{Cu} N \mathrm{NP}$}

After cooling down to room temperature, $\mathrm{NaCl}, \mathrm{CuSO}_{4}$ and sodium ascorbate were introduced at the optimized concentration. Then, the construction of fluorescent $\mathrm{Cu}$ NPs could be triggered if the $5^{\prime}$-terminus polyT part of substrate ssDNA remained; after another incubation of $5 \mathrm{~min}$, the fluorescence emission spectra were recorded.

\section{Gel electrophoresis experiment}

In this section, $4 \%$ agarose gel electrophoresis proved the capability that Exo I could distinguish folding and unfolding SSAs. The reaction solution obtained was loaded on the gel for electrophoresis. This procedure was conducted at a constant potential of $101 \mathrm{~V}$. Finally, the images were indicated by goldview and ethidium bromide, which could be visualized via a Tanon 4200SF gel imaging system (Tanon Science \& Technology Co., Ltd., China)

\section{Results and Discussion}

\section{Sensor design}

A novel sensing platform based on polyT-templated fluorescent $\mathrm{Cu}$ NPs for detecting $\mathrm{K}^{+}$was designed, as shown in Scheme 1. In this work, we designed a label-free substrate ssDNA that could be divided into two parts. In the absence of targets $\mathrm{K}^{+}$, $3^{\prime}$-terminus SSAs parts that specifically recognize $\mathrm{K}^{+}$failed to undergo the target-induced conformational change. Because there were no second structures to protect, the substrate ssDNA including the $5^{\prime}$-terminus polyT parts was cleaved into mono- or oligonucleotide fragments by Exo I. Without any template to construct $\mathrm{Cu}$ NPs, the low fluorescent signal was detected. However, in the presence of $\mathrm{K}^{+}$, the $3^{\prime}$-terminus SSAs parts binded with $\mathrm{K}^{+}$and folded into $\mathrm{G}$-quadruplexes. These second structures resisted the degradation of $3^{\prime}$-terminus structuresensitive Exo I. Due to successful terminal protection, the 5 -terminus polyT parts remained and provided a template to construct fluorescent $\mathrm{Cu}$ NPs. According to the obvious turn-on fluorescent signal, we achieved a quantitative analysis of the $\mathrm{K}^{+}$ concentration.

\section{Performance of the method}

We synthesized fluorescent $\mathrm{Cu}$ NPs according to a previous report, and further characterised it by TEM (Fig. 1A). The monodispersed fluorescent $\mathrm{Cu}$ NPs synthesized in this study were $2-6 \mathrm{~nm}$. We also investigated the fluorescent property of synthesized $\mathrm{Cu}$ NPs. The emission and excitation spectrum (Fig. 1B) were the same as reported, ${ }^{29}$ indicating that we succeeded to form fluorescent $\mathrm{Cu}$ NPs. To investigate the feasibility of the assay, emission spectra were recorded. 

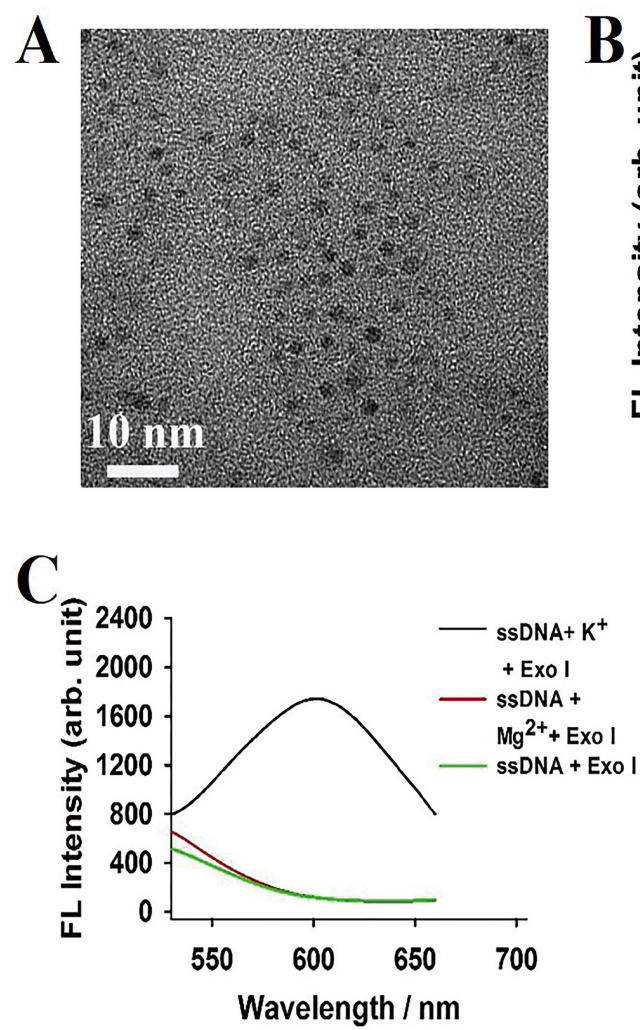
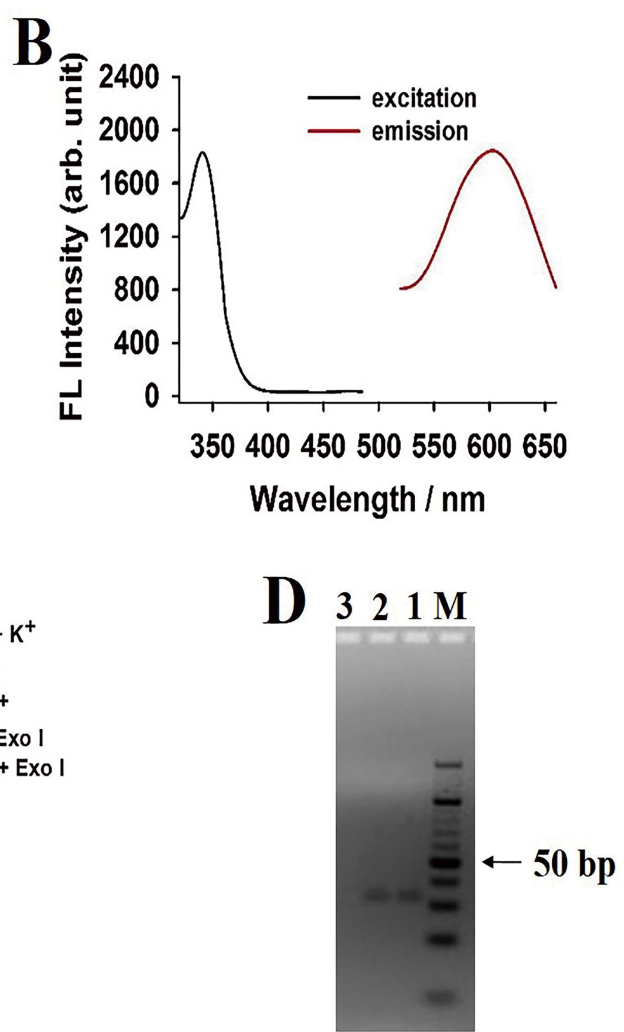

Fig. 1 (A) TEM image of Cu NPs. Scale bar, $10 \mathrm{~nm}$. (B) The maximum excitation and emission spectra of Cu NPs: excitation, $340 \mathrm{~nm}$; emission, $602 \mathrm{~nm}$. (C) Fluorescence intensity of $4 \mu \mathrm{M}$ ssDNA and $20 \mathrm{U}$ Exo I under a different reaction system: black, with $5 \mathrm{mM} \mathrm{K}^{+}$; red, with $2 \mathrm{mM} \mathrm{Mg}^{2+}$; green, without $\mathrm{K}^{+}$. (D) Agarose gel electrophoresis images of in the absence or presence of Exo I and $\mathrm{K}^{+}$; lane 1, $4 \mu \mathrm{M}$ ssDNA; lane 2, $4 \mu \mathrm{M}$ ssDNA pre-incubated with $2 \mathrm{mM} \mathrm{K}^{+}$then added $20 \mathrm{U}$ Exo I incubated for 90min; lane 3, $4 \mu \mathrm{M}$ ssDNA incubated with $20 \mathrm{U}$ Exo I for $90 \mathrm{~min}$.

As shown in Fig. 1C, in the presence of $\mathrm{K}^{+}(5 \mathrm{mM})$, the system showed strong fluorescence emission at a wavelength of about $602 \mathrm{~nm}$ when excited at a wavelength of $340 \mathrm{~nm}$ (curve a), while in the absence of $\mathrm{K}^{+}$, the signal was very weak (curve c). We then tested the influence of $\mathrm{Mg}^{2+}$, which had the same concentration as it was in the binding reaction buffer, what we observed was that the fluorescence was as weak as the system without $\mathrm{K}^{+}$(curve b). These results revealed that the presence of $\mathrm{K}^{+}$was a vital element to produce fluorescence. We also proved efficient terminal protection by the gel electrophoresis experiment (Fig. 1D). In the absence of $\mathrm{K}^{+}$, there was no band in lane 3 after introducing Exo I. Only when we added $\mathrm{K}^{+}$, could the substrate ssDNA remain, and show a band in lane 2, which was consistent with reports before that the SSAs parts only specifically recognized $\mathrm{K}^{+}$and then folded into G-quadruplexes to prevent the cleavage reaction of Exo I. ${ }^{20}$ On the basis of above data and images, we successfully synthesized $\mathrm{Cu}$ NPs and proposed a new analytical method to detect $\mathrm{K}^{+}$.

\section{Optimization of experimental conditions}

In order to obtain the desirable performance and optimal signal responses of the method, some vital parameters, such as the system of $\mathrm{Cu}$ NPs synthesis, units of Exo I, cleavage reaction time, concentration of copper ion $\left(\mathrm{Cu}^{2+}\right)$ and ascorbate, we carried out optimization experiments. Firstly, we investigated the systems of $\mathrm{Cu}$ NPs synthesis among Tris-HCl, HEPES, MOPs and water (Fig. 2A). The result indicated that all of them were suitable environments to form $\mathrm{Cu}$ NPs. But considering the repeatability of a previous experiment, ${ }^{20}$ we chose Tris-HCl as the reaction buffer. The units of Exo I have a great effect on the fluorescent signal intensity because insufficient Exo I may not cleave the ssDNA totally, and any remaining polyT may cause a false positive signal. Considering the duration of our method, we chose $120 \mathrm{~min}$ as the longest reaction time we can accept, and then optimize the units of Exo I. Figure 2B indicates that in a 120-min cleavage reaction time, at least $20 \mathrm{U}$ Exo I could cleave the substrate ssDNA completely. We then chose $20 \mathrm{U}$ Exo I to optimize the cleavage reaction time. From Fig. 2C, we observed that the fluorescent intensity decreased from 0 to $120 \mathrm{~min}$, and reached a platform when having reacted for $90 \mathrm{~min}$. We chose a 90-min reaction time as the optimal condition. As the fluorescent signal, $\mathrm{Cu}$ NPs formation is one of the vital procedures in this method. After investigating the influences of $\mathrm{Cu}^{2+}$ and ascorbate, which were important conditions in the process of forming $\mathrm{Cu}$ NPs (Figs. 2D and 2E), the optimized concentrations of $500 \mu \mathrm{M} \mathrm{Cu}{ }^{2+}$ and $2 \mathrm{mM}$ ascorbate were used in subsequent research.

\section{The detection of $\mathrm{K}^{+}$}

The fluorescence responses toward various $\mathrm{K}^{+}$concentrations, as shown in Fig. 3A, depicted that in the absence of $\mathrm{K}^{+}$, the fluorescence intensity was very weak. This result was ascribed to the cleavage of polyT and a failure of fluorescent $\mathrm{Cu}$ NPs construction. However, adding $\mathrm{K}^{+}$to the reaction system and increasing its concentrations from $50 \mu \mathrm{M}$ to $10 \mathrm{mM}$ led to a gradual increase of the fluorescent signal, and eventually to a 
A

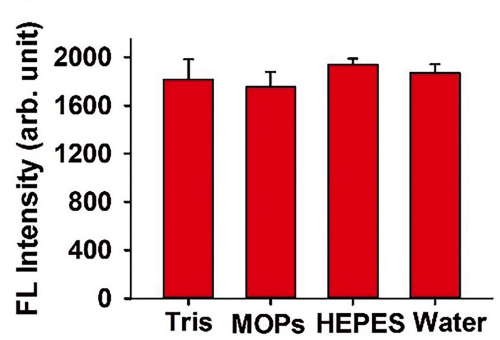

B

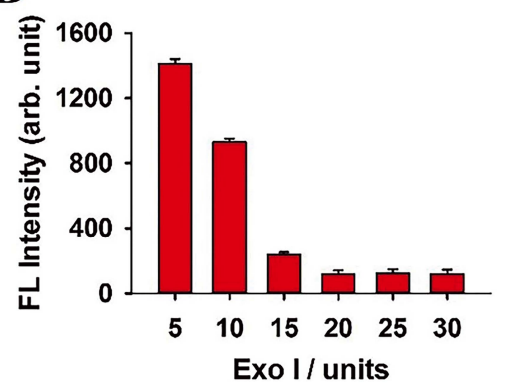

C

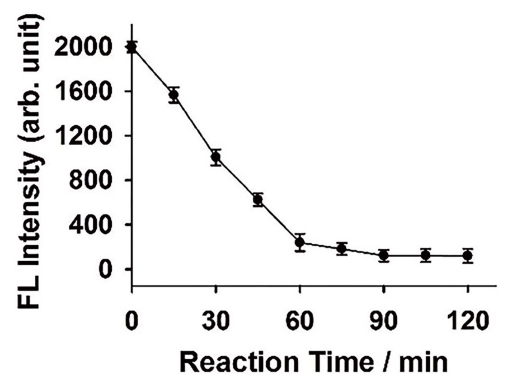

D

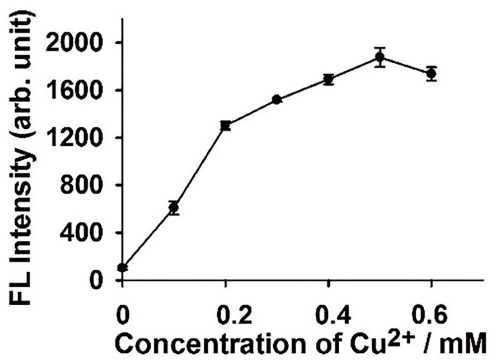

$\mathbf{E}$

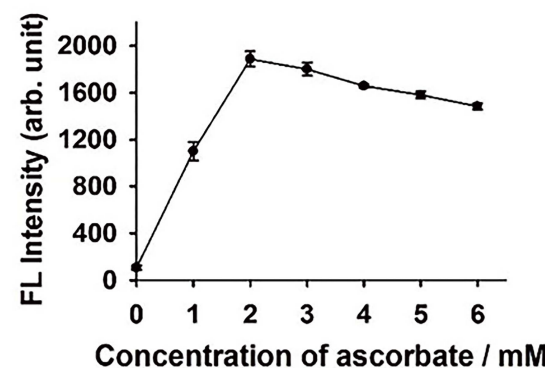

Fig. 2 (A) Fluorescence intensity in different reaction solution ( $2 \mu \mathrm{M}$ ssDNA, $150 \mathrm{mM}, \mathrm{NaCl}, 2 \mathrm{mM}$ ascorbate, $0.45 \mathrm{mM} \mathrm{CuSO}_{4}$ ). All of the buffer was $20 \mathrm{mM}, \mathrm{pH}$ 7.6. (B) Fluorescence intensity changes of $\mathrm{Cu}$ NPs in 120 min with various amount of Exo I from 5 - $30 \mathrm{U}$. (C) Fluorescence intensity changes of different Exo I cleavage time from $0-120 \mathrm{~min}$. (D) Cu NPs in buffered solution (20 mM Tris-HCl, $2 \mathrm{mM} \mathrm{MgCl}, 150 \mathrm{mM} \mathrm{NaCl}, \mathrm{pH}$ 7.6). Effect of the synthetic conditions at $\lambda_{\mathrm{em}}=602 \mathrm{~nm}$ after adding different $\mathrm{Cu}^{2+}$ concentration. The concentration of $\mathrm{Cu}^{2+}$ is $0,0.1,0.2,0.3,0.4,0.5$ and $0.6 \mathrm{mM}$, respectively. (E) Effect of the synthetic conditions at $\lambda_{\mathrm{em}}=602 \mathrm{~nm}$ after adding different ascorbate concentration. The concentration of ascorbate is $0,1,2,3,4,5$, and $6 \mathrm{mM}$, respectively.
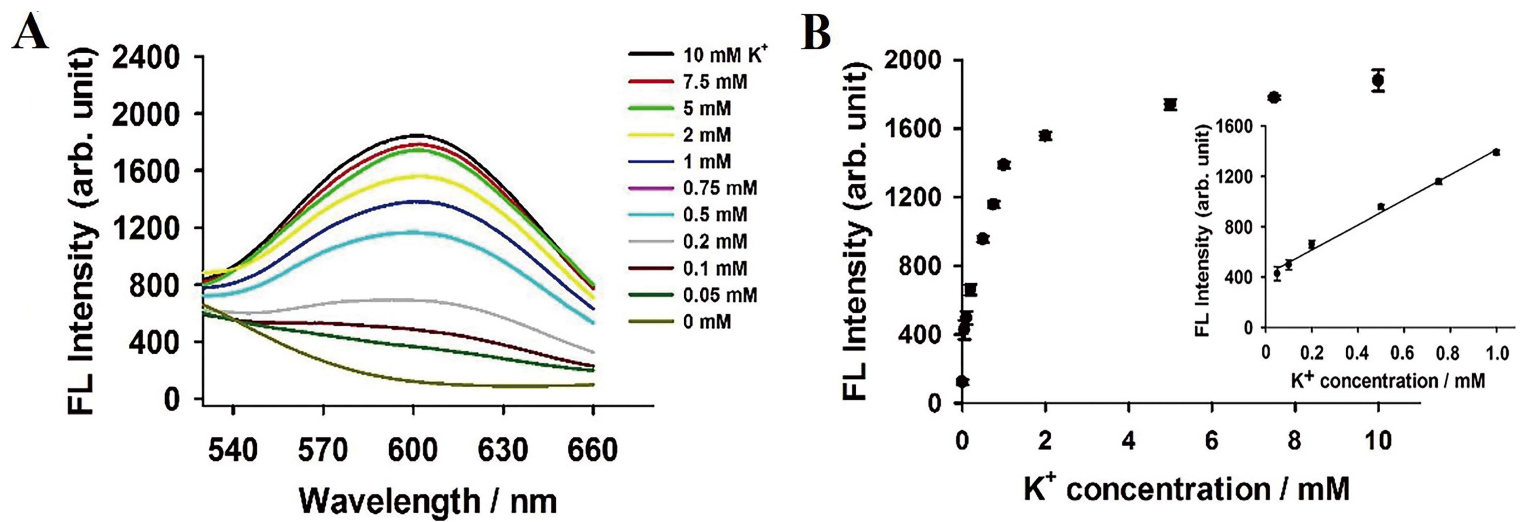

Fig. 3 (A) Fluorescence spectra of the sensing system in the presence of different concentrations of $\mathrm{K}^{+}$. (B) Fluorescence spectra response at $602 \mathrm{~nm}$ versus the $\mathrm{K}^{+}$concentration. Inset showed the linear response of the assay to $\mathrm{K}^{+}$. Error bars represented standard deviations from three repeated experiments.

platform. This observation demonstrated that relying on the exceptional structure-sensitivity capability of Exo I, the SSAs could prevent the cleavage of Exo I after incubating with $\mathrm{K}^{+}$. These findings suggested that this method indeed offers a specific and sensitive platform for $\mathrm{K}^{+}$detection under the bestcase conditions.

The strong fluorescent peak at $602 \mathrm{~nm}$ linearly correlated with the $\mathrm{K}^{+}$concentration in the range from 0.05 to $1 \mathrm{mM}$, as shown in Fig. 3B. The calibration equation was $F=994.275 c+$ 416.614 with a regression coefficient of $R^{2}=0.991$, where $c$ represents the $\mathrm{K}^{+}$concentration $(\mathrm{mM})$. The limit of detection
(LOD) was estimated to be $0.05 \mathrm{mM}$ according to the $3 \sigma$ rule. The sensitivity of this method is lower than those previously reported (Table 1), suggesting that a feasible and potential biosensor for sensitive $\mathrm{K}^{+}$assays has been successfully demonstrated.

\section{The specificity and selectivity}

To verify the specificity of the method, a selectivity experiment was investigated under the same conditions by examing the fluorescence response to $\mathrm{Na}^{+}, \mathrm{Mg}^{2+}, \mathrm{Ca}^{2+}, \mathrm{NH}_{4}^{+}, \mathrm{Li}^{+}$and a mixture of $\mathrm{Na}^{+}$and $\mathrm{K}^{+}$. As shown in Fig. 4, an obvious 
Table 1 Comparison of the proposed method with other methods for $\mathrm{K}^{+}$detection

\begin{tabular}{llc}
\hline \multicolumn{1}{c}{ Method } & \multicolumn{1}{c}{ Technique } & Detection limit/mM \\
\hline Optical & Colorimetric $^{30}$ & 1 \\
Electrochemical & Potentiometric $^{31}$ & 0.0727 \\
Optical & Fluorescence $^{32}$ & 0.4 \\
Optical & Colorimetric $^{33}$ & 0.1 \\
Optical & Fluorescence $^{34}$ & 0.1 \\
Optical & Fluorescence $^{35}$ & 0.5 \\
Optical & Fluorescence (this work) & 0.05 \\
\hline
\end{tabular}

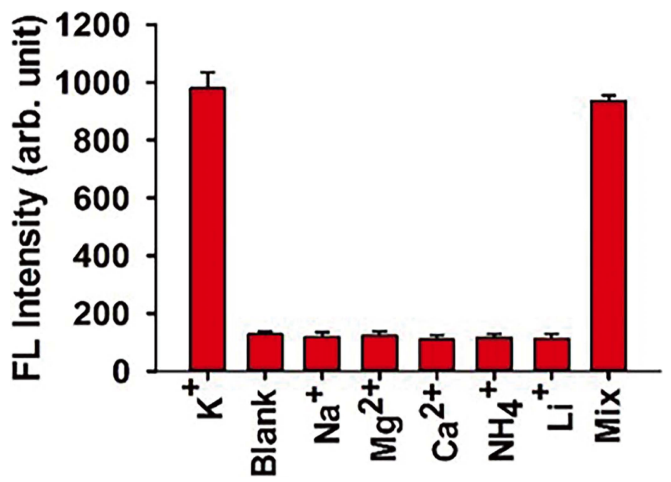

Fig. 4 Changes of fluorescence intensity in the presence of $0.5 \mathrm{mM}$ $\mathrm{K}^{+}$and $5 \mathrm{mM}$ of other ions. "Mix" is a mixture of $0.5 \mathrm{mM} \mathrm{K}^{+}$and $1.5 \mathrm{mM} \mathrm{Na}^{+}$.

Table 2 Detection of the $\mathrm{K}^{+}$in real samples

\begin{tabular}{cccc}
\hline Sample & ICPMS/mM & Found $/ \mathrm{mM}$ & Ratio, \% \\
\hline 1 & 0.08 & 0.065 & 81.25 \\
2 & 0.26 & 0.209 & 80.28 \\
3 & 0.83 & 0.706 & 85.06 \\
\hline
\end{tabular}

fluorescence enhancement was observed only when $\mathrm{K}^{+}$was present, while other ions showed no significant fluorescence intensity increase, since other ions could not trigger folding of the SSAs parts into G-quadruplexes to resist Exo I digestion. This result revealed the excellent specificity of the method for detecting $\mathrm{K}^{+}$against other metal ions.

\section{Detecting $K^{+}$in human serum}

Clinically, detecting $\mathrm{K}^{+}$in a biological sample is important for disease diagnostics. It is reported that to keep the normal biological environment, the level of $\mathrm{K}^{+}$in serum must be $3.5-5.5 \mathrm{mM}^{20}$ We then applied this method to detect $\mathrm{K}^{+}$in diluted human serum. As can be seen in Table 2, the desirable result revealed that this biosensor had great feasibility in real biological systems.

\section{Conclusions}

In summary, a specific biosensor based on a terminal protection strategy and fluorescent $\mathrm{Cu}$ NPs was demonstrated for $\mathrm{K}^{+}$ detection. Compared with other assays, this label-free method eliminates the need for using the traditional organic dye and labeling of ssDNA, which greatly reduces the cost. As far as we know, this work is the first $\mathrm{K}^{+}$detecting method that combines exceptional structural sensitivity of Exo I with fluorescent $\mathrm{Cu}$ NPs. Additionally, the principle can be employed to the detection of other targets, like small molecules, proteins, and to further study the interaction between aptamers and biological targets.

\section{Acknowledgements}

This work was supported by the National Natural Science Foundation of China (Nos. 21525522 and 21275045).

\section{References}

1. H. He, M. A. Mortellaro, M. J. Leiner, R. J. Fraatz, and J. K. Tusa, J. Am. Chem. Soc., 2003, 125, 1468.

2. P. Kofuji and E. A. Newman, Neuroscience, 2004, 129, 1045.

3. H. C. Kuo, C. F. Cheng, R. B. Clark, J. J. Lin, J. L. Lin, M. Hoshijima, V. T. Nguyêñtrân, Y. Gu, Y. Ikeda, and P. H. Chu, Cell, 2001, 107, 801.

4. S. Takenaka and B. Juskowiak, Anal. Sci., 2011, 27, 1167.

5. S. P. Yu, L. M. Canzoniero, and D. W. Choi, Curr. Opin. Cell Biol., 2001, 13, 405.

6. M. Tanha, S. K. Chakraborty, B. Gabris, A. S. Waggoner, G. Salama, and D. Yaron, J. Phys. Chem. A, 2014, 118, 9837.

7. T. T. Ruckh, C. G. Skipwith, W. Chang, A. W. Senko, V. Bulovic, P. O. Anikeeva, and H. A. Clark, ACS Nano, 2016, 10,4020

8. B. Kim, I. H. Jung, M. Kang, H. K. Shim, and H. Y. Woo, J. Am. Chem. Soc., 2012, 134, 3133.

9. A. D. Ellington and J. W. Szostak, Nature, 1990, 346, 818.

10. T. Zhao, R. Liu, X. Ding, J. Zhao, H. Yu, L. Wang, Q. Xu, X. Wang, X. Lou, and M. He, Anal. Chem., 2015, 87, 7712.

11. S. Eissa and M. Zourob, Anal. Chem., 2017, 89, 3138.

12. Z. Wu, H. Li, and Z. Liu, Sens. Actuators, B, 2015, 206 , 531 .

13. D. Shangguan, Y. Li, Z. Tang, Z. C. Cao, H. W. Chen, P. Mallikaratchy, K. Sefah, C. J. Yang, and W. Tan, Proc. Natl. Acad. Sci. U. S. A., 2006, 103, 11838.

14. Y. Yang, Y. Cen, W. J. Deng, R. Q. Yu, T. T. Chen, and X. Chu, Anal. Methods, 2016, 8, 7199.

15. Z. Wu, E. Xu, M. F. Chughtai, Z. Jin, and J. Irudayaraj, Food Chem., 2017, 230, 673.

16. J. L. Yao, X. Gao, W. Sun, X. Z. Fan, S. Shi, and T. M. Yao, Inorg. Chem., 2012, 51, 12591.

17. G. Zhu, H. Zhang, O. Jacobson, Z. Wang, H. Chen, X Yang, G. Niu, and X. Chen, Bioconjugate Chem., 2017, 28, 1068.

18. F. Atabi, S. L. M. Gargari, M. Hashemi, and P. Yaghmaei, Iran J. Pharm. Res., 2017, 16, 35.

19. A. Vallée-Bélisle and K. W. Plaxco, Curr. Opin. Struc. Biol., 2010, 20, 518.

20. D. Zheng, R. Zou, and X. Lou, Anal. Chem., 2012, 84, 3554.

21. Z. Wu, Z. Zhen, J. H. Jiang, G. L. Shen, and R. Q. Yu, J. Am. Chem. Soc., 2009, 131, 12325.

22. Y. Wei, Y. Chen, H. Li, S. Shuang, C. Dong, and G. Wang, Biosens. Bioelectron., 2015, 63, 311.

23. M. L. Firdaus, I. Fitriani, S. Wyantuti, Y. W. Hartati, R. Khaydarov, J. A. Mcalister, H. Obata, and T. Gamo, Anal. Sci., 2017, 33, 831.

24. M. Okochi, T. Kamiya, T. Omasa, M. Tanaka, and 
H. Honda, Anal. Sci., 2016, 32, 93.

25. J. Chen, X. Ji, and Z. He, Anal. Chem., 2017, 89, 3988

26. Z. Qing, X. He, D. He, K. Wang, F. Xu, T. Qing, and X. Yang, Angew. Chem., 2013, 52, 9719.

27. H. B. Wang, H. D. Zhang, Y. Chen, K. J. Huang, and Y. M. Liu, Sens. Actuators, B, 2015, 220, 146.

28. T. Qing, X. He, D. He, X. Ye, J. Shangguan, J. Liu, B Yuan, and K. Wang, Biosens. Bioelectron., 2017, 94, 456.

29. P. Ni, Y. Sun, S. Jiang, W. Lu, Y. Wang, Z. Li, and Z. Li, Sens. Actuators, B, 2017, 240, 651 .

30. L. Wang, X. Liu, X. Hu, S. Song, and C. Fan, Chem
Commun., 2006, 3780.

31. M. F. S. Teixeira, B. H. Freitas, P. M. Seraphim, L. O. Salmazo, M. A. Nobre, and S. Lanfredi, Pro. Chem., 2009, 1, 293.

32. C. Shi, H. Gu, and C. Ma, Anal. Biochem., 2010, 400, 99.

33. X. Zhu, J. Zhao, Y. Wu, Z. Shen, G. Li, and A. Chem, Anal. Chem., 2011, 83, 4085.

34. J. Lee, H. J. Kim, and J. Kim, J. Am. Chem. Soc., 2008, 130,5010 .

35. T. Li, E. Wang, and S. Dong, Anal. Chem., 2010, 82, 7576. 